\title{
Development of new functional food products based on spreads
}

\author{
Chobit M., Panchenko Yu., Vasylyev V., Usiichuk M. \\ Institute of Chemistry and Chemical Technologies, Lviv Polytechnic National University, UKRAINE, Lviv, \\ 3/4 pl. Sviatoho Yura, e-mail: maksym.r.chobit@lpnu.ua
}

\begin{abstract}
The aim of this work was to determine the types of butter as a raw material for the development of new formulations of spreads using vegetable oils and the creation of new functional products. As a result, we obtained an improved functional food product with improved quality characteristics and developed a method for its production.
\end{abstract}

Keywords - butter, spreads, flax oil, linen cake extract, functional products.

The concept of "spreads" came into circulation recently. Spreads are safer in terms of nutrition compared to butter and other animal fats. They meet the requirements of a healthy diet, as they have a balanced content of fatty acid residues and are enriched with vitamins. The production of spreads is young, so there are many issues that need to be addressed, ranging from improving the regulatory framework and ending with the consumer sphere. Currently, the cause of all the typical problems of modern nutrition is excessive consumption of high-calorie foods, persistent deficiency of vital components, as well as unbalanced diet.

Our diet is too high in fat, salt, sugar and very little fresh vegetables and fruits. The definition of "healthy eating" means the use of a variety of products, mainly of plant origin in the optimal ratio to provide the body with all necessary nutrients. In this context, emulsion fat products, which include spreads, deserve special attention. They contain a small amount of saturated fats, which are a risk factor for health and no cholesterol; they contain the necessary vitamins, minerals, dietary fibre, antioxidants. Providing the population with high-quality food is the most important economic and social problem. The leading role in its implementation belongs to the dairy and oil and fat industry.

The aim of this work was to determine the types of butter as a raw material for the development of new formulations of spreads using vegetable oils and the creation of new functional products. As a result, we obtained an improved functional food product with improved quality characteristics and developed a method for its production.

To create new functional products, we chose linseed oil, which has a high content of unsaturated fatty acids: 44-61\% $\alpha$-linolenic (Omega-3), 15-30\% linoleic (Omega-6), 13-29\% oleic -9). The content of saturated acids is $9-11 \%$. Flaxseed oil is obtained by cold pressing, so this product does not undergo heat treatment and does not lose its properties due to the destruction of useful elements at high temperatures.

The effect of temperature on the consistency of two types of butter with a fat content of $63 \%$ and $72.5 \%$ was studied. As a result of the experiments, it was found that the optimal temperature is $30^{\circ} \mathrm{C}$, and the optimal time for melting butter is 30 minutes.

In order to form a variety of tastes in the spreads and create new functional products, we have developed sweet cream spreads with a fat content of $69.2 \%, 73 \%$ and $78 \%$. The raw materials for their production were sweet cream butter "Sandwich" with a fat content of 63\%, linseed oil (vegetable component), for which the optimal amount was determined, milk powder (to normalize fat content) and water.

In the studies we used the flaxseed extract (ELM) obtained by us, the feature of which is the content of lignans. These are phenolic compounds that have estrogenic properties. In addition, flaxseed meal is rich in vitamins B, E and folic acid, very useful for the digestive system. It contains $30-35 \%$ protein, more than $30 \%$ nitrogen-free extractives and $8-9 \%$ fiber. 
Table.1. Appearance of spreads based on sweet butter with fat content $72,5 \%$.

\begin{tabular}{|l|l|l|l|}
\hline Quality & $\mathbf{8 0 \%}$ & $\mathbf{8 2 , 5 \%}$ & $\mathbf{8 5 \%}$ \\
\hline $\begin{array}{l}\text { Appearance at content } \\
\text { temperature } \\
5-7^{\circ} \mathrm{C}\end{array}$ & & & \\
\hline $\begin{array}{l}\text { Appearance on the cut } \\
\text { Appearance at room } \\
\text { (for } 15\end{array}$
\end{tabular}

Flax mucus soothes the gastric mucosa, relieves inflammation, and fiber promotes the excretion of toxins. The cake also contains iron, magnesium, potassium and other trace elements. The extracted components acted as a food additive with the potential functions of filler, stabilizer and emulsifier. The determined optimal amount of ELM partially weakens the yellow colour of the spread. The consistency of the finished product becomes more plastic, at room temperature the spread slowly melts and is easily spread on bread. ELM enhances the smell of flax in spreads and does not affect the taste.

In the studies we used the flaxseed extract (FE) obtained by us, the feature of which is the content of lignans. These are phenolic compounds that have estrogenic properties. In addition, flaxseed meal is rich in vitamins B, E and folic acid, very useful for the digestive system. It contains 30-35\% protein, more than 30\% nitrogen-free extractives and 8-9\% fiber. Flax mucus soothes the gastric mucosa, relieves inflammation, and fiber promotes the excretion of toxins. The cake also contains iron, magnesium, potassium and other trace elements. The extracted components acted as a food additive with the potential functions of filler, stabilizer and emulsifier. The determined optimal amount of FE partially weakens the yellow color of the spread. The consistency of the finished product becomes more plastic, at room temperature the spread slowly melts and is easily spread on bread. FE enhances the smell of flax in spreads and does not affect the taste.

\section{Conclusion}

Thus, as a result of research, a method of obtaining new functional products - spreads with improved quality characteristics, which contain unsaturated fatty acids, a complex of vitamins, easily absorbed by the human body and can be used for healthy eating. The composition of ingredients for different types of butter as raw materials for spreads is optimized. Flaxseed oil with valuable useful properties as a component of vegetable fat in the received functional products is applied. The use of flaxseed extract as a food additive with the potential properties of a stabilizer, emulsifier and useful filler is proposed. The complex of researches of physicochemical and organoleptic properties and the constructed profilograms testify to the conformity of the obtained DSTU products and allowed to determine their best formulations. 